\title{
Perspectivismo e interpretação na filosofia nietzschiana
}

\author{
Roberto de Almeida Pereira de Barros*
}

\begin{abstract}
Resumo: Apesar das poucas referências ao termo, a noção de perspectividade formulada por Nietzsche constitui um pressuposto importante de sua reflexão filosófica. Trata-se de uma noção, como se buscará demonstrar, significativa para a compreensão de muitos posicionamentos teóricos do autor relativos à ciência e ao conhecimento e decisivamente na interpretação de ambas as noções como perspectivas interpretativas. A argumentação a seguir visa analisar as influências e pressupostos desta noção, evidenciando seu pano de fundo kantiano (neokantiano), schopenhauriano, mas também considerando influências exteriores à filosofia, tal como a física teórica de Ruggero Boscovich, que tem importância decisiva na formulação das noções de perspectividade e interpretação perspectivista na filosofia de Nietzsche.
\end{abstract}

Palavras-chave: consciência, sujeito, perspectividade, interpretação.

\footnotetext{
* Professor da Universidade Federal do Pará, Belém, PA, Brasil.

Correio eletrônico: robertbarr@gmx.net
}

54 Cad. Nietzsche, Guarulhos/Porto Seguro, v.39, n.1, p. 54-92, janeiro/abril, 2018. 


\section{Introdução temática}

O ambiente filosófico no qual a reflexão de Nietzsche ocorre é o de crise da filosofia idealista e de uma alteração do quadro epistemológico referente à relação entre filosofia e ciências naturais. No contexto destas ocorreram nas primeiras décadas do século XIX mudanças de posicionamentos que geraram implicações diretas nesta mudança de estatuto. O surgimento da física teórica, mais propriamente da termodinâmica e dos estudos sobre propagação do calor por radiação, marca um ponto de virada no que se refere à hegemonia do parâmetro científico implícito na física de Newton, fundado na formulação matemática de leis naturais que regem o mundo físico sensorialmente perceptível. Estes novos campos de investigação indicavam uma forte tendência, de cunho formalista, prioritariamente matemático, das ciências naturais ${ }^{1}$. Simultaneamente, no âmbito das ciências biológicas, ocorria também um redimensionamento da influência do modelo mecanicista no que concerne a questões biológicas $^{2}$, assim como uma forte tendência evolucionista das pesquisas, que não deixaram de causar significativo impacto no meio filosófico, decisivamente no que se refere à fisiologia e à psicologia. No ambiente filosófico alemão, após a morte de Hegel, em 1831, o direcionamento naturalista resultou, a partir da década de 50, no neokantismo, o assim denominado movimento emblematicamente caracterizado pelo apelo de "retorno a Kant!", efetuado por Otto Liebemann no seu Kant e os seus epígonos (1865). O neokantismo é significativo por caracterizar o recrudescimento de uma reação filosófica própria da filosofia moderna frente ao naturalismo ${ }^{3}$, que tendia a desqualificar epistemologicamente a filosofia caracterizando-a

1 Cf. Omnès, 1996, p. 151.

2 Cf. Frezzatti, 2003, p. 437.

3 Um primeiro contra movimento pode ser interpretado na crítica de Wolf à filosofia imanentista de Espinosa.

Cad. Nietzsche, Guarulhos/Porto Seguro, v.39, n.1, p. 54-92, janeiro/abril, 2018. 
a partir da posição idealista. Naquele momento, o criticismo kantiano, enquanto posição filosófica não metafísica, diferenciada do idealismo que lhe fora posterior, parecia ser a saída mais segura para a defesa da importância da filosofia ${ }^{4}$, pois o giro copernicano kantiano determinara a questão da subordinação do objeto ao sujeito cognoscente, a partir do pressuposto da possibilidade deste mesmo sujeito de estabelecer os limites da própria capacidade de conhecer e devendo estar o conhecimento em concordância elucidativa com a experiência sensória. Para os neokantianos estes postulados deveriam novamente servir de marco regulatório para o pensamento filosófico, os quais poderiam possibilitar demonstrar a sua capacidade de adequação à nova conjuntura epistemológica. Desse modo o neokantismo é digno de nota, pois readequou uma problemática central para a filosofia alemã a partir do século XVII; a necessidade de regular os limites da pesquisa empírica e de estabelecer os seus domínios, que deveria resultar em uma análise filosófica dos princípios fundantes e conhecimentos das ciências. ${ }^{5}$

No que se refere a Nietzsche, é importante notar que consideradas as influências da filosofia de Schopenhauer, o interesse pelas obras de Friedrich Albert Lange, (A história do materialismo e crítica de sua significação na atualidade, 1866) ${ }^{6}$, de Johann Zöllner (Sobre a natureza dos cometas, 1872), de African Spir (Pensamento e efetividade, 1873), dentre outros, demonstra emblematicamente este caráter, pois todos os autores supra citados partiram, mesmo que de forma diferenciada, do pressuposto de validade do conceito de consciência formulado por Kant para efetuarem críticas ao pressuposto da plena autonomia das ciências naturais.

Seja vista sob a ótica da filosofia de Schopenhauer ou sob o ponto de vista da grande importância da reflexão de Lange para Nietzsche,

4. Cf. Schnädelbach, 1984, p.18.

5 Cf. Holzhey, 2002, p. 21.

6 Primeiro volume publicado em 1865, segundo volume em 1875.

$56 \mid$ Cad. Nietzsche, Guarulhos/Porto Seguro, v.39, n.1, p. 54-92, janeiro/abril, 2018. 
uma interpretação do traço perspectivista de sua filosofia sem a devida observância destes aspectos apresenta-se como significativamente restritiva. A sua recepção da diferenciação feita por Schopenhauer entre sujeito do conhecimento e eu sensório, por conseguinte, da consideração do primeiro como "substratum do mundo" e do segundo como uma ilusão identificatória advinda do desconhecimento da determinante dimensão volitiva inerente à vida, resulta na filosofia de Nietzsche no aprofundamento da consideração fisiopsicológica de pressupostos gnosiológicos e morais da filosofia e da ciência, que explicitam seu interesse pelas discussões fisiológicas que as pesquisas de Lamarck e de Darwin haviam colocado no centro das investigações biológicas acerca da origem da vida.

Todavia, a partir de março de 1873, intermediado pelas leituras de Lange e do livro de T. Fechner Sobre as teorias atômicas física e filosófica (1864), Nietzsche toma contato com postulados do físico croata Ruggero Boscovich e com isso acirra contato com a tendência teórica da física moderna. Greg Withlock ${ }^{7}$ defende a significação decisiva do croata com respeito à "teoria da realidade" de Nietzsche, que ele então associa às hipóteses do eterno retorno e da vontade de potência. Por conseguinte, Whitlock argumenta no sentido de indicar a associação feita por Nietzsche entre os posicionamentos de Boscovich concernentes à dissolução da matéria e a crítica do atomismo filosófico de Espinosa, que para o filósofo ainda se faria presente tanto na filosofia como na física de seu tempo ${ }^{8}$. Estes são aspectos importantes para a reflexão de Nietzsche acerca do problema da relação entre matéria e intelecto, que perpassa as filosofias crítica e idealista, alcançando tanto a filosofia de Arthur Schopenhauer como a análise de Lange do materialismo, e se faz presente de modo central na sua filosofia, decisivamente no que se refere a questões relativas ao problema da justificação do conhecimento. A convergência destes

7 Cf. 1996, p. 204.

8 Idem, p. 216.

Cad. Nietzsche, Guarulhos/Porto Seguro, v.39, n.1, p. 54-92, janeiro/abril, 2018. $\mid \mathbf{5 7}$ 
Barros, R. A. P.

aspectos é o tema deste artigo e ela será abordada a partir de três pontos básicos: A) O da recepção de Nietzsche do movimento de retorno à filosofia de Kant marcado para ele pela consideração da história do materialismo de Lange. B) A percepção de Nietzsche, tanto por intermédio da filosofia de Schopenhauer quanto das pesquisas de Boscovich, das limitações restritivas do modelo de conhecimento de cunho kantiano e idealista, fundado na relação sujeito - objeto e no modelo causal de interpretação. C) A concepção perspectivista da filosofia do autor tendo em vista os aspectos acima mencionados, que o levam a conceber uma filosofia fortemente pautada no princípio da interpretação em oposição a pretensões deterministas.

\section{Kant e a Perspectividade na Filosofia Alemã}

Que a filosofia crítica pode ser interpretada como uma necessária resposta da filosofia racionalista ao empirismo e aos seus desdobramentos, nos esclarece o próprio Kant. No prefácio para a segunda edição de sua Crítica da razão pura, ao tentar subordinar a razão às condições de possibilidade da experiência (Krv/CrP, B XXXVI, 36), o filósofo de Königsberg acredita poder esclarecer a forma inerente do conhecer humano por meio da explicitação da relação entre sensibilidade, entendimento e razão, evidenciando suas ligações, alcances e limites. Baseado nos resultados do exitoso modelo mecanicista de Newton, fundado na elucidação teórica do equilíbrio das forças estruturantes do mundo natural a partir dos princípios de atração, pressão e impulso, Kant considera o sujeito (consciência) como o ponto necessário de unidade entre os objetos e o princípio da validade objetiva dos juízos referentes a eles, o que ele chama de unidade transcendental da autoconsciência [tranzendentalen Einheit des Selbstbewusstseins] (Krv/CrP B 132, p. 136), que nada mais é que o eu pensante em sua estrutura lógico-categorial mais ampla, elementar e fundante. A racionalidade transcendental, a pura racionalidade que mobiliza logicamente conceitos, é responsável

$58 \mid$ Cad. Nietzsche, Guarulhos/Porto Seguro, v.39, n.1, p. 54-92, janeiro/abril, 2018. 
pela formulação dos Juízos sintéticos a priori, aqueles que não necessitam da experiência para a sua confirmação, mas esclarecem os princípios elementares de funcionamento da efetividade (Krv/CrP B XIII, XIV, p. 23). Em sua atividade transcendental, a razão passa a definir o que deve ser tomado como os princípios elementares da própria experiência, pois "a unidade analítica da apercepção só é possível sob o pressuposto de alguma unidade sintética" (Krv/CrP B 134, p. 137). Nesse sentido, a filosofia crítica de Kant, muito embora estabeleça um ponto de vista novo para a filosofia moderna, segue os direcionamentos desta iniciado pela filosofia cartesiana ${ }^{9}$ e assim confirma a racionalidade autorreferente como a única via possível para o conhecimento. Fichte e $\mathrm{Hegel}^{10}$, mesmo que a partir de interpretações bastante particulares da filosofia crítica, colocamse como continuadores desta linha de consideração ${ }^{11}$. Dentre vários outros pontos, dois aspectos são de particular importância para esta consideração. Aquele que os aproxima ao anseio de Kant em dar à razão uma finalidade prática e o problema da liberdade (Krv/CrP B XXIX), que se torna o tema central da especulação filosófica alemã até Hegel. ${ }^{12}$

A inversão da perspectiva empirista empreendida pelo autor da Crítica da razão pura, que com ela objetivou demonstrar a dependência da matéria das estruturas cognitivas do entendimento e da razão, por conseguinte, demonstrar que a razão pode suplantar a necessidade referencial sensória inicial do entendimento e formular juízos que se reportam ao mundo, mas que não mais dependem de sua percepção direta para serem formulados ${ }^{13}$, consiste em aspecto determinante para os direcionamentos da filosofia acadêmica alemã

9 Cf. Pearson, 2001, p. 14.

10 Schelling, por questões argumentativas, não pode ser considerado aqui.

11 Cf. Henrich, 2003, introdução, p. 8.

12 Cf. Sedgwick, 2000, p. 1.

13 Cf. Kaulbach, 1990, p. 22

Cad. Nietzsche, Guarulhos/Porto Seguro, v.39, n.1, p. 54-92, janeiro/abril, 2018. 
Barros, R. A. P.

que se desenvolveu a partir dela. Com efeito, se com a filosofia de Kant a racionalidade humana é colocada no centro de todo o jogo de aferição da existência e de possibilidades de referencialidade da efetividade [Wirklichkeit], não se trata mais de especular unicamente acerca das possibilidades de percepção e de referencialidade do intelecto ante o mundo, mas de afirmar que este apenas poderia ter sentido [Sinn], se fosse compreendido como produto daquele. Apenas a racionalidade compreendida em sua interação e superioridade com respeito a sensibilidade e ao intelecto pode explicitar as formas mais elementares e universais da efetividade, entendida como um todo organizado logicamente por meio de leis fixas. Apenas ela pode ultrapassar a limitação epistemológica da mera percepção sensível ${ }^{14}$ e, portanto, através disso, formular princípios universais e necessários de modo apriorístico (Krv/CrP B XIX, 26).

Todavia, ao demonstrar a possibilidade teórica dos juízos sintéticos a priori, Kant transpõe os limites especulativos estabelecidos entre teórico e prático e busca responder a questão "o que devo fazer?". Pergunta que ele acredita poder ser respondida por meio da demonstração da incondicionalidade e da necessidade prática dos juízos sintéticos a priori. Com isso a sua revolução copernicana coloca a racionalidade como centro necessário do pensar e da ação e, por isso, a fonte de determinação da liberdade. Este posicionamento, com efeito, será fortemente colocado em questão por Schopenhauer e por Nietzsche, mesmo considerado que ambos também sejam críticos do reducionismo materialista da atividade científica. Não é possível tratar aqui de todos os pormenores deste movimento especulativo, sem dúvida um dos mais significativos e complexos da história da filosofia. Nós nos limitaremos a indicar alguns pontos centrais e decisivos para a argumentação aqui desenvolvida, no que concerne à compreensão de pressupostos do caráter perspectivistico que Nietzsche mobiliza em sua filosofia.

14 Cf. Redding, 2009, p. 53.

$60 \mid$ Cad. Nietzsche, Guarulhos/Porto Seguro, v.39, n.1, p. 54-92, janeiro/abril, 2018. 
Como primeiro aspecto indica-se a pretensão da filosofia alemã posterior a Kant de considerar a efetividade entendendo-a como um constructo logicamente elaborado pelo sujeito racional e, em uma perspectiva referencial, subordinada a este. Em segundo lugar, o caráter autorreferencial da concepção de racionalidade, que pressupõe a possibilidade de ela mesma fornecer os fundamentos da sua primazia sobre a sensibilidade. Finalmente, o princípio do limite do conhecimento, compreendido enquanto constructo da consciência e, por conseguinte, limitado às possibilidades desta.

Essas noções permanecem fundantes para as filosofias de Fichte e Hegel e são decisivas para a compreensão dos posicionamentos filosóficos subsequentes e que buscaram se distanciar delas, aqui prioritariamente consideradas as filosofias de Schopenhauer e de Nietzsche. A menção a estes pressupostos histórico-filosóficos com vistas à consideração do perspectivistico nietzschiano tem por objetivo primeiro mostrar como o autor compreende a percebe a crise da filosofia idealista e, a partir dela, identifica este modelo interpretativo não como crítico ou especulativo, mas moral-religioso.

\section{A crise da filosofia idealista alemã}

Com a morte de Hegel, a filosofia acadêmica alemã sofre a perda de seu último grande nome no século XIX ${ }^{15}$. Após Hegel a reflexão filosófica com pretensões revisionistas desenvolvida em solo germânico se dá essencialmente fora das universidades. Schopenhauer, com sua breve passagem pela universidade de Berlim, não pode ser computado como um filósofo acadêmico. $\mathrm{O}$ mesmo se aplica a Nietzsche, cuja produção filosófica se deu prioritariamente em âmbito não institucional.

15 Cf. Mayerhofer/Vanecek, 2007, p. 9.

Cad. Nietzsche, Guarulhos/Porto Seguro, v.39, n.1, p. 54-92, janeiro/abril, 2018. |61 
Barros, R. A. P.

A morte de Hegel marca o fim da pretensão da filosofia acadêmica, marcantemente constatável em Fichte ${ }^{16}$, de afirmar o idealismo enquanto ato livre do pensar autorreferente ${ }^{17}$, como o âmbito no interior do qual o conceito de ciência deveria ser pensado e mesmo reformulado, pois a consciência deveria conter o fundamento universalizante daquilo que lhe é exterior. Com a inserção da ideia de uma identidade dinâmica da consciência para formular uma interpretação totalizante da história entendida como percurso da consciência em busca da superação da alienação com respeito a si mesma, Hegel buscara superar as limitações tanto do idealismo como das ciências naturais, presas aos seus objetos específicos, por meio de uma teodiceia racional segundo a qual a razão (Espírito), a ultimativa autoconsciência, forneceria a chave para a interpretação e unificação de todas as esferas que constituem a efetividade, isto, todavia, sob o signo da adequação da consciência produtora de conceitos à dinâmica histórico-temporal da efetividade.

A filosofia teria por função evidenciar conceitualmente o traço absoluto da efetividade ${ }^{18}$, necessitando para isso superar a visão compartimentada e restritiva do saber empírico ou formalista. Ao conferir historicidade às manifestações da consciência, Hegel afastase não apenas do formalismo que ele identifica na concepção de unidade sintética da autoconsciência da filosofia de Kant ${ }^{19}$, como do desejo de verdade absoluta e estável. Verdade se torna para ele processo, pois é vista como a compreensão das contradições da efetividade, entendidas em uma perspectiva universal e dinâmica. Para Hegel o saber apenas é efetivo enquanto sistema, que deve expressar a totalidade em sua unidade na temporalidade.

16 Cf. Sedgwick, introdução, 2000, p. 8.

17 Cf. Henrich, 2003, p. 301.

18 Cf. Redding, 2009, p. 141.

19 Cf. Brinkmann, 2011, p. 63.

$62 \mid$ Cad. Nietzsche, Guarulhos/Porto Seguro, v.39, n.1, p. 54-92, janeiro/abril, 2018. 
Os pressupostos centrais da filosofia de Hegel buscam ultrapassar em amplitude a visão de mundo que era então formulada pelas ciências naturais, por ele consideradas como referencialmente redutoras. Mesmo a física ainda estaria presa a uma mera conceituação da experiência sensível, ficando, portanto, presa a ela. Esta limitação deveria ser então superada pela filosofia da natureza, que pensaria em maior amplitude e de modo unificado os conceitos formulados pelas ciências ${ }^{20}$, dando a elas uma significação no todo da reflexão sobre a efetividade, conferindo à filosofia um cunho científico pautado na sistematicidade universalizante, porém concreta (Enciclopédia II, p. 21 -28).

Histórica e cientificamente esta pretensão filosófica do Zeitgeist de Hegel ${ }^{21}$ de, a partir da consciência universalizante expressar a totalidade da efetividade em sua existência e unidade dinâmica, enquanto absoluto, não se confirmou. Os domínios científicos tenderam para graus maiores de particularização e evidenciaram as dificuldades epistemológicas de uma síntese de suas especificidades. Disso decorreu um maior distanciamento das ciências naturais da reflexão filosófica, em clara vantagem para as primeiras, restando à filosofia apenas a possibilidade de iniciar um movimento de reaproximação com o positivismo naturalista, norteado pela ideia de esclarecimento de problemas relativos ao conhecimento ${ }^{22}$, que seria decisivo para os posicionamentos filosóficos ulteriores. Nietzsche ocupou-se intensamente com esta problemática.

20 Cf. Stone, 2014, p. 92.

21 Cf. Löwith, 1969, p. 226.

22 Como seria emblematicamente expresso por Eduard Zeller em seu livro de 1862, Sobre o significado e tarefa da teoria do conhecimento. 
Barros, R. A. P.

\section{O dogmatismo imanentista de Schopenhauer}

Que a filosofia de Schopenhauer possui uma significativa importância para Nietzsche é ponto pacífico. Todavia, o que nos ocupará aqui não serão os inúmeros aspectos que as conectam, mas apenas os pontos decisivos que se referem ao perspectivismo nietzschiano. Neste sentido, deve ser primeiramente considerada a posição limítrofe que a filosofia de Schopenhauer ocupa com respeito à filosofia ${ }^{23}$. Ainda que pautada em uma perspectiva sistemática de pensamento, todavia cônscia das possibilidades de clausura da filosofia sistemática, Schopenhauer evidencia a pretensão imanentista de fornecer um modo de interpretação da efetividade a partir de um princípio metafísico essencial. Mesmo partindo de pressupostos centrais da teoria do conhecimento kantiana, sua filosofia afasta-se de forma marcante da filosofia pautada no conceito de consciência que caracteriza a filosofia alemã de Kant a Hegel. Ao conceber a razão como submetida à vontade, inseparavelmente ligada ao corpo (WWV I/MV I § 24, p. 182), e este como primeira de manifestação daquele princípio metafísico fundante do mundo, Schopenhauer mobiliza um primeiro ponto indicador das fragilidades da concepção idealista do pressuposto da autonomia da consciência em sua pretensão gnosiológica.

A sua filosofia imanentista rejeita a possibilidade de uma interpretação incondicionada do funcionamento das categorias transcendentes e às subordina à tendência da vontade em manifestarse no mundo da representação. Para Schopenhauer razão e corpo, lógica e fisiologia, não poderiam mais ser pensadas separadamente. Mesmo as categorias apriorísticas da sensibilidade, imprescindíveis ao entendimento e à razão, espaço, tempo, e ainda o princípio lógico da causalidade, exprimiriam apenas uma justificação lógica da indução (WWV I/MVR I, § 4, p. 42), que estaria submetida às necessidades

23 Cf. Koßler, 2006, p. 366.

64 Cad. Nietzsche, Guarulhos/Porto Seguro, v.39, n.1, p. 54-92, janeiro/abril, 2018. 
impostas pela vontade e expressas da nossa constituição fisiológica. Elas seriam responsáveis pela formulação de estruturas representativas do mundo visto apenas enquanto fenômeno para um sujeito (WWV I/ MVR I, § 1, p. 31), estando este, porém, primeiramente condicionado pela constituição orgânico-volitiva e não por autodeterminação lógica (WWV I/MVR I, § 6, p. 57). Por conta disso, para Schopenhauer uma compreensão última, total, da efetividade não pode ser alcançada pela mera descrição fenomênica do mundo, pois o princípio determinante deste, a vontade enquanto fundamento metafísico, não pode ser apreendida pelas formas humanas de percepção e conceituação e, por isso, não pode ser representada. $\mathrm{O}$ conhecimento pleno do mundo, tal como Kant já anunciara, permanece inacessível, nos restando apenas a representação do mundo fenomênico, sempre parcial e inconclusa, pois ela apenas pode expressar de forma limitada a livre infinitude da vontade.

A visão de mundo do sujeito do conhecimento está, portanto, sempre restrita às limitações dos aparatos sensório e intelectivo do homem, ficando a coisa em si, a vontade, inalcançável e apenas limitadamente intuível, da qual os mais altos graus de percepção é a ideia, a "plena objetivação da vontade", sua "ADEQUADA OBJETIVIDADE" (ADEQUÄTE OBJEKTIVITÄT) ${ }^{24} \mathrm{e}$ a experiência estética da música. Seja como fenômeno, seja como representação, o mundo permanece, também para Schopenhauer, dependente do sujeito que o percebe e representa. Estas duas formas de relação com o mundo estão para ele subordinadas à estrutura orgânica do homem que, por seu turno, está submetida à vontade, entendida como origem das condições de compreensão e de significação [Deutung] do mundo ${ }^{25}$. Desse modo, a relação entre intelecto, um instrumento da vontade, e o real por ele percebido se altera significativamente. $\mathrm{O}$ objetivo primeiro do intelecto não é o conhecimento do mundo, mas servir à

24 Schopenhauer.WWV INMV I §34, p. 245.

25 Cf. Lesniewska, 2006, p. 349.

Cad. Nietzsche, Guarulhos/Porto Seguro, v.39, n.1, p. 54-92, janeiro/abril, 2018. 
Barros, R. A. P.

vontade como meio para a tendência desta de manifestar-se em graus cada vez mais elevados e distanciados com respeito ao mundo físico, por conseguinte em graus cada vez mais elevados de objetividade (WWV I/MVR I § 51, p. 324). É assim que Schopenhauer interpreta tanto a ideia platônica quanto a matemática, as criações artísticas e as categorias racionais transcendentes, como formas de exteriorização [Selbstäußerung] da vontade. Por meio delas a vontade evidencia a aspiração por uma estabilidade no mundo fenomênico, mas que não pode ser alcançada em dimensões materiais da existência, fortemente submetidas ao movimento destrutivo da volição incessante, caracterizada pela "luta de todas as aparências da vontade entre si, inclusive nos mais baixos níveis de objetividade da vontade" (WWV I/MVR I $\$ 27$, p. 209).

Se por intermédio de Schopenhauer Nietzsche não apenas se aproxima das ciências naturais ${ }^{26}$, mas igualmente toma contato com dois aspectos decisivos para a inclinação perspectivista e interpretativa de sua filosofia. Uma concepção imanente da filosofia ${ }^{27}$ significa ter como intenção a compreensão do mundo na sua manifestação não valorada, ou seja, ter por objetivo esclarecê-lo na sua efetividade, sendo para isso necessário libertar o pensar do comprometimento com a sistematicidade que norteia a filosofia racionalista. Em segundo lugar, ele se defronta de forma crítica com o problema da autonomia da racionalidade com relação ao corpo, que ele compreende como pressuposto decisivamente moral. Estes pontos parecem não perder significação mesmo considerado o posterior afastamento de Nietzsche com respeito à metafísica schopenhauriana, a partir de seu contato com as obras de Rudolf Haym e de Friedrich Albert Lange. ${ }^{28}$

26 Cf. Koßler, 2006, p. 375.

27 Cf. Barros, 2015, p. 84.

28 Cf. Lopes, 2011, p. 24.

$66 \mid$ Cad. Nietzsche, Guarulhos/Porto Seguro, v.39, n.1, p. 54-92, janeiro/abril, 2018. 


\section{O proto neokantismo de Friedrich Albert Lange}

A referência é mais do que conhecida, em uma carta de agosto de 1866, endereçada a Carl von Gesdorff, Nietzsche expressa o seu entusiasmo para com o recém adquirido livro de Friedrich Albert Lange, publicado no ano anterior, História do Materialismo e crítica de seu significado na atualidade. Tal menção se dá pouco depois do então jovem doutorando da universidade de Leipzig ter se defrontado com o Opus magnum de Arthur Schopenhauer, O mundo como vontade e representação, nos últimos dias de outubro de 1865 . O segundo achado não deixa de ter efeito sobre o primeiro ${ }^{29}$. Em um ambiente marcado pela ascensão das ciências naturais, o fenomenalismo de Lange parece para Nietzsche possuir bases científicas mais sólidas que a metafísica schopenhauriana ${ }^{30}$. Lange tenta retomar, influenciado pela filosofia de Kant, a questão da relação entre matéria e espírito ${ }^{31}$. Ele o faz considerando a importância da posição materialista de seu tempo ${ }^{32}$, como já o próprio subtítulo da obra indica. Com efeito, no prefácio da segunda edição Lange menciona a "raiz transcendente da essência humana", enquanto a verdadeira morada [Heimat] de seu espírito [Geist]. Na seção intitulada "A nova filosofia", em seu primeiro tópico, "Kant e o materialismo", Lange se refere ao movimento de retorno a Kant como resultado do fracasso da filosofia romântica ${ }^{33} \mathrm{e}$ indica este movimento em seu tempo não apenas no que concerne à filosofia (Schopenhauer), mas também aos cientistas, como resultado da percepção desse fracasso, mas também como fruto da compreensão dos limites do materialismo por parte dos cientistas naturais. $\mathrm{O}$ kantismo de Lange, contudo, não é nem ortodoxo nem dogmático, ele

29 Cf. Stack, 1983, p. 11.

30 Idem, p. 13.

31 Cf. Stack, introdução, 8.

32 Cf. Mayerhofer/Vanecek, 2007, p. 13.

33 Cf. Lange, 1887, p. 355.

Cad. Nietzsche, Guarulhos/Porto Seguro, v.39, n.1, p. 54-92, janeiro/abril, 2018. |67 
Barros, R. A. P.

é crítico, e se baseia decisivamente no princípio do giro copernicano e na pressuposição de que este demonstra os limites e o ceticismo da posição materialista ${ }^{34}$. Lange busca se opor ao pressuposto de que uma interpretação conclusiva do mundo possa ser alcançada por meio da pesquisa empírica das ciências, pois para ele Kant já havia demonstrado que a percepção sensível e as representações produzidas a partir delas pelo sujeito jamais ultrapassam o registro referencial dos objetos. Ele reafirma o pressuposto da filosofia kantiana, segundo o qual um ultrapassamento da percepção imediata e da sua limitação quantitativa só pode ser obtido por meio da consciência em sua capacidade apriorística de formular juízos sintéticos, o que indica um direcionamento posterior de sua argumentação para o campo moral.

Afastando-se de qualquer interpretação metafísica desse tipo de juízo, Lange reafirma, por meio dos resultados da matemática, da álgebra e da aritmética, o valor da confirmação prática destes postulados eminentemente teóricos ${ }^{35}$, nos quais se revela o caráter de necessidade dos mesmos ${ }^{36}$. Mas a meta prioritária de Lange é mostrar a relação de intransponível dependência entre experiência e intelecto, a partir dos postulados segundo os quais a organização do pensamento é anterior à experiência e que o intelecto fornece as primeiras condições desta $^{37}$. Para Lange, estes aspectos são resultados da pesquisa fisiológica, que demonstra "que em impressões sensórias, inicialmente compreendidas como desconexas, agem por processos que, por meio de eliminação ou acréscimo de conhecidos encadeamentos lógicos [logische Mittelglieder], expressam significativamente as conclusões e equívocos do pensamento consciente." ${ }^{\text {38 }}$.

34 Idem, 1887, p. 363.

35 Idem, p. 639.

36 Idem, p. 671.

37 Idem, p. 382.

38 Idem, p. 386.

$68 \mid$ Cad. Nietzsche, Guarulhos/Porto Seguro, v.39, n.1, p. 54-92, janeiro/abril, 2018. 
A longa consideração crítica de Lange de aspectos centrais da filosofia kantiana desenvolvida neste capítulo chega ao seu fim com uma defesa da filosofia prática de Kant, fundamentalmente no que diz respeito à questão da liberdade. Desse modo, Lange permanece fiel à posição de que o reducionismo materialista possui consequências negativas para a abordagem de questões relativas à ética. Ao entender a coisa em si como conceito limite e as noções de alma, mundo e Deus como produtos de nossa organização racional e de nossa inclinação à unidade ${ }^{39}, \mathrm{o}$ autor tenta demonstrar a validade da relação de determinação entre percepção intuitiva e conceito racional que Kant afirma na Crítica da razão pura e que possui decisiva significação para a sua filosofia moral. Para Lange o juízo moral não deve se basear na experiência, mas possuir autonomia com respeito a ela e, desse modo, ser justificado pelo seu caráter ideal de possibilidade ${ }^{40}$. Neste sentido a filosofia kantiana se baseia no pressuposto teórico e não prático da liberdade, na possibilidade de o homem entender-se como Noumenon e não como Phänoumenon ${ }^{41}$. Assim sendo, ele deve buscar no ensinamento do ideal racional a justificativa da moralidade. Lange interpreta este último aspecto como a fusão no pensamento de Kant entre poesia [Dichtung] e ciência [Wissenschaft], uma associação que viria a se tornar, justamente com o caráter ideal de ensinamentos, aspecto tão importante para Nietzsche, muito embora com padrões bastante distintos de formulação.

\section{A física matemática de Boscovich}

Registros significativos da recepção e do impacto das ideias de Boscovich sobre Nietzsche são as referências ao croata feitas em duas cartes endereçadas a Heinrich Köselitz, a primeira datada

39 Lange, 1887, p. 408.

40 idem, 413.

41 idem, 214.

Cad. Nietzsche, Guarulhos/Porto Seguro, v.39, n.1, p. 54-92, janeiro/abril, 2018. 
Barros, R. A. P.

na primeira metade de 1882 e a segunda no fim de agosto de 1883 . Ambas constam no volume 6 das cartas publicadas pela edição crítica (Kritische Studieausgabe) das obras de Nietzsche sob a supervisão de Giorgio Colli e Mazino Montinari. Na primeira delas, de número 213 e escrita em Gênova em 20 de maio de 1882, encontram-se indicações importantes de pontos que mobilizaram o interesse de Nietzsche pela física de Boscovich. Nela o filósofo contrapõe a concepção matemática do croata à "rustica e ingênua" posição de Robert Mayer com respeito à matéria [Stoff] e se refere ao jesuíta como um "opositor da aparência visível" [Augenscheins]. Para Nietzsche nesta passagem Boscovich marcaria o fim da simplificação popular [populäre Erleichterung] da "existência da matéria" (KSB 6, p. 183) e com isso teria indicado novos rumos para a pesquisa atômica.

Ele levou a teoria atômica ao seu término [zu Ende gedacht]. Peso [Schwere] não é sabidamente nenhuma "qualidade da matéria", simplesmente porque não existe matéria. Gravidade [Schwerkraft] é, do mesmo modo, algo como a vis inertiae, sabidamente uma forma de manifestação [Erscheinungsform] da força [Kraft]: Apenas que a relação lógica desta forma de manifestação outra, por exemplo calor, ainda não é plenamente visualizável [noch ganz undurchsichtig] (KSB 6, p. 183).

Nietzsche busca combater a ideia, que em Mayer e seus seguidores é indicada como crença, da existência do átomo pleno [Erfüllte Atome], que ele associa à concepção unitária de força [Eine Kraft], a qual para ele deveria ser descreditada. Contrariamente a isso, Nietzsche afirma que a teoria cinética [Kinetische Theorie] necessita [muss] "reconhecer os átomos pelo menos exteriormente à energia cinética [Bewegungsenergie] e ainda ambas as forças de coesão e gravidade [Schwere $]^{\text {"42 }}$ - o que é feito por físicos e químicos e ainda

42 Ibidem. Schwere é neste momento traduzido como gravidade dada a anterior indicação de Nietzsche, segundo a qual o peso é uma relação de forças e não uma qualidade da matéria. Neste sentido parece ser possível aproximar peso e gravidade, sendo que a opção por este último termo torna mais claro o pressuposto da argumentação, que é o de afirmar a multiplicidade de forças.

$70 \mid$ Cad. Nietzsche, Guarulhos/Porto Seguro, v.39, n.1, p. 54-92, janeiro/abril, 2018. 
por seguidores de Mayer, mas que não os fez abandonar a presunção de uma força unitária. Nietzsche lhes imputa então a presunção de que assim o fazem, devido cogitarem ainda uma segunda força como pano de fundo, o primum mobile, o "amado Deus", junto ao movimento. Na segunda carta, escrita em Sils-Maria, Nietzsche se refere a sua ocupação com a teoria atômica até os "Quadrantes [Quartanten] do jesuíta Boscovich, o primeiro a demonstrar matematicamente que a pressuposição [Annahme] do átomo pleno [Erfüllter Atompunkte] seria uma hipótese inútil [unbrauchbare] para a ciência rigorosa da mecânica" (KSB 6, p. 442). Nietzsche toma esta proposição como canônica junto a cientistas naturais apoiados na matemática, mas a considera indiferente [gleichgultig] para a prática da pesquisa [Praxis der Forschung].

Destas duas cartas gostaríamos de ressaltar três aspectos centrais para a presente argumentação. 1. A crítica da noção intuitiva de átomo e de matéria. 2. A crítica da insistência na manutenção desta ideia por estar vinculada a uma noção causal de força, que para Nietzsche tem a teologia como pano de fundo. 3. A questão da justificação matemática do posicionamento teórico, que assim se contrapõe às noções intuitivas. A datação das cartas não deve levar à compreensão de que estes pressupostos são temas de interesse de Nietzsche a partir da década de oitenta. Anotações relativas a estes temas já podem ser encontradas no início de 1873 - portanto um ano após o contato de Nietzsche com os escritos de Boscovich ${ }^{43}-\mathrm{e}$ estão documentadas no volume 7 da KSA, onde é mencionada uma teoria atomístico-temporal [Zeitatomlehre], que pressupõe tanto a compreensão das limitações das formas de representação baseadas em sensações (Nachlass/FP 26 [11], início de 1873, KSA 7.574), quanto uma interpretação não intuitiva do tempo, que resulta na dissolução dos corpos físicos [Körper] em uma linearidade temporal infinitesimal (Nachlass/FP 26 [12], início de 1873, KSA 7.576). As

43 Cf. Whitlock, 1996, 200.

Cad. Nietzsche, Guarulhos/Porto Seguro, v.39, n.1, p. 54-92, janeiro/abril, 2018. 
Barros, R. A. P.

conclusões destes pressupostos são hipotéticas e partem da ideia da ação à distância da força [actio in distans temporis punctum], que devido à hipótese do fracionamento infinito do tempo, leva Nietzsche a recusar a ideia unitária de força.

"Nós teríamos então uma força pontual, que teria uma relação em cada momento temporal futuro de sua existência, isto é, cuja força residiria em cada figura e relação. Em cada mínimo momento seria necessário que a força fosse diferente" (Nachlass/FP 26 [12], início de 1873, KSA 7.578)

Dadas as características da representação intuitiva, Nietzsche acredita que isso seria transposto para proporções adequadas ao mundo existente, tendo em vista a visualização espaciais destas "proporções de força" [Sichtbarwerdung dieser Kraft-Proportionen]. Nos apontamentos isso parece servir como esclarecimento crítico para a manutenção na física atômica do seu tempo da noção de forças

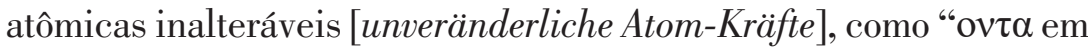
sentido parmenídico" (Nachlass/FP 26 [12], início de 1873, KSA 7.578). Contrariamente a isso, o filósofo se posiciona em favor da hipótese segundo a qual, "apenas forças absolutamente mutáveis [absolut veränderliche] atuam, aquelas que em nenhum momento são as mesmas. Todas as forças são apenas função do tempo" [Funktion der Zeit]. Dessa forma, as forças seriam gradações de aceleração [Die Kraft liegt im Grad der Beschleunigung], que equacionaria aceleração e desaceleração com a distância do efeito, o que faz com que em momento algum a força seja a mesma (Nachlass/ FP 26 [12], início de 1873, KSA 7.578). Nietzsche pressupõe então qualidades dinâmicas para a consideração do mundo visto como forças e com isso resume a sua teoria atômico-temporal [Zeitatomlhere] em três pontos:

1) reconduzir o mundo existente a uma atomística espacial pontual [punktuelle Raumatomistik];

72 | Cad. Nietzsche, Guarulhos/Porto Seguro, v.39, n.1, p. 54-92, janeiro/abril, 2018. 
2) reconduzir esta novamente a uma atomística temporal [Zeitatomistik];

3) a atomística temporal coincide finalmente com a teoria da sensação. O ponto temporal dinâmico [Der dynamische Zeitpunkt] é idêntico ao ponto sensível. Pois não existe nenhuma sincronia da percepção (Nachlass/FP 26 [12], início de 1873, KSA 7.579).

Muito se poderia escrever acerca destas anotações, o que remeteria, porém, a argumentação para direções mais específicas da teoria atomística-temporal de Nietzsche. Gostaríamos de nos restringir a um ponto específico que se refere tanto ao perspectivismo quanto a sua concepção filosófica de interpretação: a adequação de um pressuposto teórico para um referencial sensório, tal como é indicado no terceiro ponto da teoria. Este aspecto é significativo em dois sentidos, primeiramente por demonstrar o caráter perpesctivístico de toda forma de representação e interpretação, mesmo da matemática, o que demonstra o caráter intransponível da perspectividade. $\mathrm{O}$ segundo aspecto diz respeito à superação de um eventual significado negativo da perspectividade por meio de procedimentos formais que, entretanto, devem ser reconduzidos a representações intuitivas, o que pode justificar a dissolução em movimento da noção de materialidade estável [stoffliche]. Nem perspectividade, nem dedução matemática, logram livrar o homem da representação baseada na sensação, aspecto que Nietzsche mobiliza para alterar o significado da premissa kantiana que pressupõe o mundo como dependente das leis do intelecto, portanto como representação deste. Para Nietzsche compreender o mundo como representação significa compreendê-lo como erro (MA I/HDH I 19, KSA 2.41), mas é precisamente o reconhecimento deste erro que a sua filosofia deseja mobilizar como ganho interpretativo, tendo em vista a formulação de novos pressupostos interpretativos da efetividade imanente. Finalmente, mesmo que o nome de Boscovich 
Barros, R. A. P.

não seja mencionado nestes apontamentos, a proximidade temática destes com as cartas anteriormente mencionadas deixam poucas dúvidas com respeito à influência de seus postulados sobre Nietzsche e da importância de noções da sua física teórica para a concepção do perspectivismo (Nachlass/FP 40 [39], agosto-setembro de 1885, KSA 11.648) ${ }^{44}$.

\section{O caráter interpretativo da perspectividade}

Se considerada a tese de Georg L. Stack, segundo a qual Nietzsche deve a Lange boa parte dos pressupostos de sua filosofia e que o antropomorfismo da sua teoria do conhecimento advém disso, então pode-se especular que a reflexão sobre o conhecimento de Nietzsche tem no movimento de retorno à filosofia kantiana na segunda metade do século XIX o seu ponto de partida ${ }^{45}$. Todavia, como se tentará aqui argumentar, bem no espírito deste movimento - que pretendia ir "além de Kant"46 - Nietzsche empreende uma mudança de pressupostos motivado pela assimilação da crítica schopenhauriana da autonomia da razão e pela recepção de pressupostos do dinamismo da física de Boscovisch ${ }^{47}$, que o levam a afastar-se dos pressupostos do conhecimento como resultado possível de uma relação entre consciência e objeto.

António Marques também acentua a proveniência kantiana da interpretação do caráter antropomórfico do conhecimento em Nietzsche, que Stack especifica, remontando-a a Lange. Paul

\footnotetext{
44 Whitlock (2000, p. 36) menciona o empréstimo de livros de Boscovich, mas também de Spir e Zöllner junto a biblioteca da universidade da Basiléia em 28.03.1873 e, ainda, que as anotações teriam sido feitas entre esta data e 05.04 do mesmo ano, as quais, para o comentador, compõem uma interpretação própria das posições do físico croata.
}

45 Cf. Stack, 1983, p. 20.

46 Cf. Heftrich, 1998, p. 359.

47 Cf. Nasser, 2015, p. 168.

74| Cad. Nietzsche, Guarulhos/Porto Seguro, v.39, n.1, p. 54-92, janeiro/abril, 2018. 
Redding ${ }^{48}$, retornando a Leibniz, indica a concepção perspectivista do conhecimento que a filosofia kantiana possibilita e que marcaria toda a filosofia alemã posterior, aspecto que, no que se refere a uma proveniência kantiana da perspectividade, encontra aceitação em Friedrich Kaulbach. Aquilo que gostaríamos de apontar aqui são os pontos de diferenciação da interpretação de Nietzsche da perspectividade, a partir do seu contato com as novas problemáticas postas pelas ciências teóricas, dentre elas, em especial, a teoria atômico-temporal de Boscovich.

Se sob o ponto de vista fisiopsicológico é Schopenhauer que oferece a Nietzsche as primeiras indicações da prevalência do corpo, do organismo, sobre o pensar e então abre a possibilidade de interpretação das formas de intelecção como determinadas pelo organismo (VL/VM 1, KSA 1.876), parece ser a interpretação da física de Boscovich que marca em Nietzsche o distanciamento da consideração do problema da dicotomia entre fenômeno e coisa em si como problema gnosiológico e, portanto, da subordinação do conhecimento a uma consciência (MAM I/HDH I 16, 37, KSA 2.60) ou experiência em sentido kantiano ${ }^{49}$. Mesmo tomando como válida a interpretação de que Nietzsche partilha com Lange o ponto de vista segundo o qual a coisa em si se refere decisivamente não a algo real, mas ao limite de nossa capacidade de percepção e representação do mundo exterior e, ainda, aceitando que Nietzsche concorda com o princípio de que aquilo que entendemos como experiência de mundo diz respeito a uma forma de percepção limitada deste que, em última análise, expressa as necessidades humanas de percepção e de representação (Nachlass/FP 26 [11], início de 1873, KSA 7.574), ainda é necessário contrapor a isso o fato de que para Nietzsche os limites sensórios e categoriais do homem não podem ser critérios definitivos de determinação da abrangência do conhecimento. Este

48 Cf. Marques 2003, p. 58.

49 Cf. Dellinger, 2012, p. 140.

Cad. Nietzsche, Guarulhos/Porto Seguro, v.39, n.1, p. 54-92, janeiro/abril, 2018. 
Barros, R. A. P.

padrão de pensamento, determinantemente pautado pelo abandono dos pressupostos de causa e efeito e da necessidade da referência sensória como forma de legitimação do conhecimento, é ampliado por Nietzsche e aplicado à consideração das mensurações e dados mobilizados pela ciência, decisivamente pela física teórica, não mais limitada por uma interpretação causal intuitiva.

Com efeito, para Nietzsche a possibilidade de representação de uma perspectiva científica é determinada pela sua opção metodológica e pelos pressupostos desta que, para ele, estão necessariamente vinculados à estrutura elementar de funcionamento das formas de percepção e do intelecto, mas não necessariamente submetidas a elas. Aspectos mais complexos da efetividade, que não se deixam compreender por uma lógica identitária ou de grande simplicidade causal, podem ser investigados unicamente a partir de novos pressupostos e opções metodológicas distanciadas de uma intuição elementar, tendo, porém, em vista a ampliação das possibilidades de sua compreensão e não a sua determinação. Neste sentido, a metafísica substancial e a causalidade são formas simplórias e elementares de compreensão e de representação do mundo, determinadas fisiologicamente e cuja estrutura já pode ser exemplarmente encontrada na linguagem, cuja origem é pulsional. Os seus pressupostos de estabilidade, de unidade atributiva e causalidade, expressam as mais elementares formas de representação do mundo e um olhar acurado (Nachlass/FP 25 [505], primavera de 1884, KSA 11.146), fundado em resultados das ciências experimentais, deixa rapidamente à mostra as suas deficiências interpretativas e os processos de simplificação do pensamento formal. É nesse sentido que a filosofia de Kant poder ser interpretada negativamente como "ciência das fronteiras [Grenzen] da razão!", e a interpretação lógica das forças como "mitologia para o pensar" (Nachlass/FP 7 [14] final de 1886 - início de 1887, KSA 12.299).

O tema da perspectividade apresenta-se, portanto, associado a outras duas questões centrais, a da ciência entendida como interpretação

76| Cad. Nietzsche, Guarulhos/Porto Seguro, v.39, n.1, p. 54-92, janeiro/abril, 2018. 
e a questão do peso da experiência sensível e da lógica relacionada a ela com respeito a duas formas de interpretações mecânicas. Esses temas aparecem de forma clara em sua associação nos aforismos 372 , 373 e 374 de $A$ gaia ciência. No primeiro deles, intitulado "Por que não somos idealistas", Nietzsche critica simultaneamente o "temor [Furcht] dos filósofos ante os sentidos" (FW/GC 372 KSA 3.623), mas, ao mesmo tempo, o excessivo desaprender [verlernt] deste temor. Muito embora identifique que os filósofos da atualidade e do futuro de modo geral são sensualistas, Nietzsche questiona a tendência de se acreditar que "as ideias seriam ainda mais sedutoras que os sentidos", algo que ele também toma como potencialmente falso. A argumentação, porém, de tom crítico ao idealismo filosófico e a sua "descensualização" [Entsinnlichung], acaba com uma exceção feita ao idealismo platônico, pois Nietzsche exclui Platão de sua consideração do idealismo como doença e indica a ausência de saúde dos modernos para tomar o idealismo de Platão como necessário [um Plato's Idealismus nöthig zu haben], em uma referência com grande significação para o desenvolvimento da argumentação. No aforismo seguinte, por seu turno, intitulado "Ciência" como preconceito", encontra-se uma crítica tanto da interpretação da teoria do altruísmo e do egoísmo de Herbert Spencer, como dos cientistas naturais materialistas [materialistische Naturforscher], mais especificamente à crença [Glauben] destes no pressuposto de que o mundo deve possuir um equivalente e medida decorrentes do pensamento racional e dos conceitos valorativos [Werthbegriffen] dos homens ${ }^{50}$, o que Nietzsche denomina "mundo da verdade" [Welt der Wahrheit]. Em contraposição a estes pressupostos, fundados na "pequena e quadrática racionalidade humana", Nietzsche mobiliza a ideia da ciência como como interpretação de mundo [Welt-interpretation] e critica o mecanicismo desta interpretação científica, por ela se basear nos sentidos [Sinnen] e estar subordinada à matematização da

50 Cf. Stegmaier, 2011, p. 33.

Cad. Nietzsche, Guarulhos/Porto Seguro, v.39, n.1, p. 54-92, janeiro/abril, 2018. 
Barros, R. A. P.

experiência. A esse posicionamento Nietzsche associa deselegância [Plumpheit] e ingenuidade [Naivität $]$ e efetua uma crítica direta do otimismo para com uma interpretação mecânica de mundo fundada nestes pressupostos:

Uma "científica" interpretação de mundo como vós entendeis, poderia ser, em decorrência, sempre uma das mais néscias, ou seja, a mais sensualmente pobre dentre todas as interpretações de mundo: Isso dito aos ouvidos e consciências dos nossos senhores mecanicistas, que hoje gostam de circular entre os filósofos e antes de tudo pressupõem que a mecânica seria a doutrina das primeiras e últimas leis sob as quais, como um esteio, toda a existência necessitaria ser erigida. Mas, um mundo essencialmente mecânico seria um mundo essencialmente sem sentido [sinnlose]! (FW/ GC 373, KSA 3.626)

A conexão da crítica à mecânica intuitiva com a perspectividade que Nietzsche agrega a sua filosofia é indicada no aforismo seguinte, intitulado "Nosso novo "infinito", no qual o autor argumenta, com tácito afastamento de posições kantianas, em favor da impossibilidade de elaboração de uma perspectiva que não pressupunha nenhuma perspectividade. Este aspecto pode ser associado com a crítica à filosofia baseada na noção e autonomia do intelecto, que Nietzsche acomete ao mobilizar o argumento da impossibilidade deste de efetuar uma crítica de si mesmo segundo um ponto de vista exterior ao seu, pois este não pode "ver a si mesmo sob sua forma perspectivista, mas apenas nela" (FW/GC 374, KSA 3.626). Nós gostaríamos de retornar à ideia de infinitude do mundo mencionado neste mesmo aforisma no tópico final deste artigo, neste momento é mais importante continuar a ressaltar nossa hipótese interpretativa, segundo a qual Nietzsche contrapõe a física teórica ao modelo epistemológico pressuposto pelo idealismo transcendental kantiano. Argumentos em favor desse ponto de vista parecem podem ser encontrados no aforismo 335 de $A$ gaia ciência, onde, mesmo em se tratando da questão da atribuição de valor da judicação moral em uma ótica fisiológica, é a física,

78 Cad. Nietzsche, Guarulhos/Porto Seguro, v.39, n.1, p. 54-92, janeiro/abril, 2018. 
e Kant, que fornecem dados indicativos para a análise do desejo de normatividade das interpretações, precisamente porque seus formalismos interpretativos demonstram o caráter criador de sentido de toda perspectiva.

E para isso temos de nos tornar melhores aprendizes e descobridores de tudo o que é normativo e necessário no mundo: temos de ser físicos, para podermos, neste sentido, ser criadores - enquanto até agora todos os ideais e valorações foram construídos com base no desconhecimento [Unkenntniss] da física ou em contradição com ela. Por isso: Acima com a física! E mais alto ainda o que ela nos obriga - nossa probidade! (FW/GC 335, KSA 3.594)

Não se trata de atribuir um novo e mais seguro valor de verdade à física, mas de compreender a maior amplitude de interpretação e, consequentemente, de criação, de suas perspectivas. A física, tal como a matemática (FW/GC 246, KSA 3.514), tornam-se então para Nietzsche objetos de auto-observaçã $0^{51}$ do traço perspectivista da relação humana com o mundo e, portanto, aptas a desqualificar o princípio do limite da capacidade humana de compreensão da efetividade pressupostos pela filosofia crítica, a partir da compreensão de que a hipótese do limite interpretativo do homem se refere a um domínio limitado da experiência do sujeito ${ }^{52}$.

É neste sentido que podemos concordar com a posição de Dellinger, segundo a qual o perspectivismo antropomórfico de Nietzsche mostra-se como decisivamente interpretativo ${ }^{53}$. Nietzsche oferece fortes indicadores de que se afasta da posição idealista ao decididamente remeter a uma fisiopsicologia a tarefa de interpretar as pretensões fundantes relativas ao conhecimento da efetividade, desvinculando esta própria perspectiva de toda pretensão de

51 Cf. Borsche, 2011, p. 477,

52 Cf. Pearson, 2001, p. 7.

53 Cf. Dellinger, 2012, p. 141.

Cad. Nietzsche, Guarulhos/Porto Seguro, v.39, n.1, p. 54-92, janeiro/abril, 2018. 
Barros, R. A. P.

validade última. Neste sentido a perspectividade implica um novo posicionamento cético (FW/GC 51, KSA 3.415), pois não nega a possibilidade de alcance de conhecimentos, ele nega a existência da verdade ontologicamente fundada e faz isso optando pela interpretação desta como uma necessidade humana (FW/GC 110, KSA 3.469). A perspectividade de Nietzsche se distancia então da kantiana em vários pontos, mas dois devem ser aqui mencionados: pelo abandono da noção de sujeito lógico (transcendental), como pressuposto fundante do conhecimento e, em segundo lugar, pela compreensão da limitação interpretativa dos princípios de identidade espaço-temporal e de causalidade, a partir da discordância de que este último possa revelar os princípios elementares de funcionamento da efetividade. $\mathrm{Na}$ sua filosofia estes aspectos resultam na crítica fisiopsicológica dos pressupostos metafísicos e racionalistas, traço que acaba por se desdobrar em uma crítica moral do conhecimento e de sua acepção tradicional $^{54}$. Isso significa compreender leis mecânicas como reducionistas, pressupondo com isso relações naturais muito mais complexas que as nossas possibilidades de categorização por meio da lógica causal associada à experiência sensível (FW/GC 112, KSA 3.473). A partir disso, o conhecimento é relativizado e compreendido como resultado de uma opção interpretativa, afastado, portanto, de toda a tradição que o concebeu como algo fixo e determinável.

\section{Perspectivismo e valor}

Segundo Dellinger, o termo perspectivismo [Perspectivismus] foi possivelmente cunhado por Nietzsche mas não aparece de forma central na sua filosofia, a ponto do filósofo mesmo jamais tê-la declarado como perspectivista ${ }^{55}$. Todavia, tematicamente não parece ser incorreto mencionar este termo como significativo para a

54 Cf. Stegmaier, 2011, p. 32.

55 Cf. Dellinger, 2012, p. 128.

$80 \mid$ Cad. Nietzsche, Guarulhos/Porto Seguro, v.39, n.1, p. 54-92, janeiro/abril, 2018. 
compreensão de muitos dos seus posicionamentos. Como demonstra o próprio Dellinger, o termo se faz presente de forma mais enfática nos textos da segunda metade da década de 80 e isso pode ser relacionado com a leitura de Nietzsche da obra de Gustav Teichmüller, $O$ mundo efetivo e o mundo aparente. Novos fundamentos da metafísica (Breslau, 1882), que considera os conceitos de espaço, tempo e movimento como produtos de processos internos das intuições e que exteriorizados enquanto princípios interpretativos, teriam sempre uma discrepância com respeito à efetividade. Muito embora as diferenças de uso do conceito em Nietzsche e em Teichmüller, esse ponto toca diretamente a recusa e a crítica de Nietzsche à concepção metafísica de verdade e isso nas múltiplas perspectivas e aspectos que foram minimamente mencionados anteriormente. Entretanto, duas temáticas parecem dignas de maior atenção, tendo em vista a compreensão do perspectivismo: o aspecto fisiológico e a questão valorativa. $\mathrm{O}$ primeiro aspecto diz respeito à criação de sentido para a ideia de verdade, entendida enquanto traço intransponível e necessidade orgânica no homem (Nachlass/FP 14 [153], início de 1888, KSA 13.336), que aparece em vários momentos da obra de Nietzsche. Kaulbach também segue esta via e analisa as concepções de "sistema de domínio dos impulsos" [Herschaftssystem von Trieben] e de "Razão do corpo" [Vernunft ist Vernunft des Leibes], como pontos de diferenciação entre os perspectivismos de Kant e de Nietzsche, sob o ponto de vista da recusa da ideia de pura razão por parte deste ${ }^{56}$.

A verdade como necessidade de estabilidade do organismo ante a incessante dinamicidade do mundo, o caráter de utilidade da verdade como convenção - a qual, portanto, pressupõe a utilidade - são aspectos centrais da interpretação de Nietzsche do conhecimento. No prefácio escrito para o primeiro volume de Humano, demasiado humano, o autor se refere diretamente ao perspectivismo como relacionado a formas de avaliação: "Tu deves aprender a

56 Cf. Kaulbach, 1990, p. 227. 
Barros, R. A. P.

compreender o perspectivo (Perspektivische) de toda avaliação - o adiamento, dilaceração e a teleologia aparente do horizonte e tudo o que pertence ao perspectivo" (MAM I/HDH I 'prefácio' 6, KSA 2.20). Em seguida, Nietzsche associa vida, perspectiva e injustiça, demonstrando o caráter de não verdade de toda perspectiva e a sua associação ao problema da hierarquia relacionada ao poder, ao direito e à abrangência [Umfänglichkeit] das perspectivas. Estes aspectos e o contexto argumentativo das referências evidenciam que perspectividade para Nietzsche não constitui proposta epistemológica ou metodológica determinada, mas uma constatação imanente da insuperável parcialidade de toda interpretação, que assim evidencia a sua diferenciação de qualquer pretensão a objetivações conclusivas. Esse é o ponto de inter-relação entre perspectividade cognoscitiva com as perspectivas morais que constituem um foco central para Nietzsche nos seus últimos anos de reflexão.

\section{Perspectividade e interpretação}

Partamos, portanto, de três pontos indicados por Dellinger em seu longo artigo revisionista sobre o perspectivismo na filosofia de Nietzsche. Primeiramente da indicação segundo a qual Nietzsche não usa o termo perspectivismo "de forma regular a fim de oferecer um rótulo unificado, ou uma identificação de uma determinada teoria" ${ }^{97}$ e, em segundo lugar, a inclinação do intérprete em compreender perspectivas "enquanto formas de interpretação" as afastaria de uma "tese de falsificação" ou de uma "teoria do erro". A estes pode ser relacionado um outro aspecto mencionado por Dellinger, o da "realidade modesta", que poderia pressupor a afirmação da existência de uma realidade subjacente na filosofia de Nietzsche, o que constituiria um ponto extremamente problemático.

57 Cf. Dellinger, 2012, p. 138.

58 Idem, p. 141.

82 | Cad. Nietzsche, Guarulhos/Porto Seguro, v.39, n.1, p. 54-92, janeiro/abril, 2018. 
O próprio comentador apresenta respostas coerentes para estas questões, indicando corretamente o equívoco que seria pressupor que Nietzsche labora com o pressuposto de uma "metaposição neutra" que permaneceria protegida da "corrupção, falsificação, superficialização e generalização" ${ }^{\text {. P }}$. Pressupor isso seria conferir autorreferencialidade ao posicionamento de Nietzsche e o remeter ao domínio do criticismo kantiano, tese que não se sustenta ante as passagens que mencionam a ausência de limites do interpretar (FW/GC 374, KSA 3.627). Obviamente que, como se tentou mostrar anteriormente, o perspectivismo nietzschiano não pode ser apartado de uma influência kantiana ${ }^{60}$, todavia, a posição de Nietzsche parte da crítica do juízo sintético a priori de Kant e, consequentemente, do ultrapassamento da necessidade da relação sujeito-objeto como fonte do conhecimento. Se o homem é um ser que interpreta, basear inicial e necessariamente a justificação da interpretação do existente ao que é experienciado e, consequentemente, conceituado por ele, consiste em um pressuposto contrário aos pressupostos científicos que Nietzsche encontra de forma decisiva, por exemplo, na física de Boscovich. Seguindo as novas tendências científicas de seu tempo, que revelam possibilidades outras de interpretação do real para além de sua delimitação às formas espaço-temporais de identificação, Nietzsche crê ter argumentos suficientes para divergir da ideia norteadora do conhecimento apriorístico do kantismo. Para isso ele utiliza uma matriz fisiopsicológica de interpretação para mencionar uma capacidade de vida [Lebensfährig], uma "finalidade da manutenção" [Zweck der Erhaltung] (JGB/BM 11, KSA 5.25), inerente à crença na ordem, pois "a baixa intelectualidade [niedrige Intellektualität], a essência não científica, é condição da existência [Bedingung des Daseins], da ação" (Nachlass/FP 11 [286], primavera - outono de 1881, KSA 9.551). Hábito e crença incondicionada são

59 Idem, p. 151.

60 Cf. Kaulbach, 1990, p. 216. 
Barros, R. A. P.

fundamentos de todo crescimento e fortalecimento e são justificados pelo sucesso [Erfolg] e não pela verdade que, em última análise, adviria da valoração positiva do sucesso prático de uma convicção.

Se determinarmos tudo de necessário na nossa atual forma de pensamento, não teremos provado nada com respeito ao 'verdadeiro em si', mas apenas com respeito ao 'verdadeiro para nós', isto é, o existente a nós possibilitado [Dasein-uns-Ermöglichende], baseado na experiência e no processo que é tão velho, que o pensar invertido [Umdenken] é impossível. Todo a priori pertence a isso" (Nachlass/FP 11 [286], primavera - outono de 1881, KSA 9.550).

A crença na interpretação causal e no pensamento a priori advém daí. Elas são mitologias originárias [Urmithologie] (Nachlass/ FP 16 [63], outono de 1881, KSA 9.587) e criticar a crença no conhecimento apriorístico, entendendo-o como "uma incorporada mitologia original [eingefleischste Urmythologie] do tempo do mais profundo desconhecimento [Unkenntniss]" (Nachlass/FP 16 [16], Dezembro - janeiro de 1882, KSA 9.663) busca afastar do princípio kantiano a autarquia da necessidade significação do mundo [Weltdeutung]. A substituição do "como ?" [Wie], por um "por quê?" (Warum), com respeito à necessidade dos juízos sintéticos a priori (JGB/BM 11, KSA 2.26), indica a influência da sua predisposição fisiopsicológica sobre a moral, que necessitada de determinações irretorquíveis, influenciou toda "a filosofia alemã" posterior.

$\mathrm{O}$ aforismo 11 de Para além de Bem e mal é significativo, pois mostra a abrangência com a qual Nietzsche considera a filosofia legatária a Kant enquanto resposta letárgica (virtus dormitiva) à questão que ele indica como ainda presente na filosofia alemã, a do sensualismo. Nietzsche interpreta a insistência dos alemães na resposta kantiana à questão de possibilidade dos juízos sintéticos a priori a partir de uma "faculdade" [Vermögen], a uma motivação religiosa e a sua correlativa tendência ao "suprassensível" [Übersinnliche]. Com efeito, para Nietzsche a resposta kantiana, assim

84 Cad. Nietzsche, Guarulhos/Porto Seguro, v.39, n.1, p. 54-92, janeiro/abril, 2018. 
como a pergunta acerca da possibilidade destes juízos são frutos de uma crença, que ele interpreta como "meio de conservação" [Zweck der Erhaltung] de seres humanos, que necessitariam acreditar em juízos verdadeiros, "mesmo que eles que eles possam ser "juízos falsos". A alusão à necessidade dos "juízos verdadeiros" é o aspecto mobilizado por Nietzsche para afirmar que "juízos sintéticos a priori não deveriam de forma alguma "ser possíveis" [gar nicht "möglich sein sollen"], pois " a crença na sua verdade é propriamente necessária como uma crença de primeiro plano [Vordergrund-Glauben] e ilusão ótica [Augenschein], que pertence à ótica perspectiva [PerspectivenOptik] da vida" (JGB/BM 11, KSA 2.26). O aforismo finda com nova menção à permanência da virtus dormitiva da "filosofia alemã" posterior a Kant, em suas dimensões religiosas, morais e políticas.

Por si só, o parágrafo 11 já traz aspectos significativos a respeito de posicionamentos contra os quais Nietzsche emprega a ótica perspectivista. Ele tem, porém, a sua significação complementada com o parágrafo 12, escrito em tom de continuidade. Nele o autor se refere à atomística materialista [materialistische Atomistik], como a coisa mais refutável [bestwiderlegten Dinge] que existe e então agradece ao por ele considerado polonês, Ruggero Giuseppe Boscovich (em verdade croata, nascido em Ragusa, hoje Dubrovnik, em 1711), que seria o vitorioso opositor da ilusão ótica [Gegner des Augenscheins], precisamente por ter demonstrado a impertinência na crença na "matéria". A argumentação que se segue toca novamente na questão da moralização do conhecimento, manifesta na associação da "necessidade atomista" ["atomistischen Bedürfnisse"] com as conhecidas "necessidades metafísicas" ["metaphysichen Bedürnisse"] e, ainda, com a "atomística da alma" [Seelen-Atomistik] decorrente do cristianismo, que tornou a alma algo não erradicável, eterno, indivisível como uma mônada. Para Nietzsche, "Esta crença deve ser extraída da ciência!", para que então nela encontrem acolhimento novas noções relativas à alma - para além também da restrição 
Barros, R. A. P.

naturalista - tais como "alma mortal", alma como "pluralidades do sujeito", ou ainda como "estrutura social de impulsos e afetos", possibilidades que poderiam remeter a uma psicologia da invenção [Erfinden] e, talvez, da descoberta [Finden]. O propósito de Nietzsche, como fica patente na parte final do aforismo, não é a supressão da noção de alma, mas claramente se afastar da ideia substancial ou unitária desta.

Corroborando o direcionamento da presente argumentação, o aforismo conecta a questão física sobre a matéria com a psicologia, que para Nietzsche poderia pôr fim às supertições [Aberglauben] acerca das representações da alma que, como visto, para ele estão na base da crença na matéria e no átomo. Nos aforismos que se seguem, a questão fisiológica (JGB/BM 13, 15, KSA 5.27, 29 ) continua a ser apresentada entrementes uma reflexão sobre a física (§ 14). A física é considerada não como um esclarecimento do mundo [WeltErklärung], mas uma, a partir de nós, reflexão acerca do mundo [Welt-Auslegung], uma justificação [Zurechtgebung] do mundo. A sua interpretação como esclarecimento advém primeiramente da crença nos sentidos [Glauben an die Sinne], da crença segundo a qual tudo deve ser sensorialmente justificado. Neste sentido até mesmo Platão estaria à frente do imperativo moderno, fundado no princípio: "onde o homem nada mais tem para ver e tocar, lá ele também nada mais tem a buscar" (JGB/BM 14, KSA 5.28). Kant é obviamente pressuposto neste aforismo, muito embora, novamente, não diretamente mencionado, como ocorre no parágrafo 5 e em referência ao seu "imperativo categórico", indicado como conclusão dialética e "finos ardis [Tücken] de um velho moralista e pregador moral".

O ponto central destas noções é indicar a influência das perspectivas morais nas formulações filosóficas. Nas palavras de Nietzsche, "efetivamente, faz-se bem (e inteligentemente) no que se refere ao esclarecimento de como propriamente as mais basilares 
afirmações metafísicas de um filósofo se estabeleceram sempre primeiramente ao perguntar, a que moral isso quer (ele quer -) chegar, ou ultrapassar?" (JGB/BM 6,KSA 5.20). Esta vinculação da filosofia com o pressuposto da vontade ${ }^{61}$ e com os comprometimentos dos filósofos morais serve de argumento introdutório para Nietzsche mencionar o caráter perspectivistico de toda filosofia, assim como de toda busca pelo saber (JGB/BM 10, KSA 5.24) e elogia os céticos antirrealistas e micro observadores do conhecimento [skeptischen AntiWirklichen und Erkenntniss-Mikroskopikern], que instintivamente se distanciaram da "efetividade moderna" [der modernen Wirklichkeit] e caminham não de volta [zurück], mas querem se distanciar, ir além, deste passado (JGB/BM 10, KSA 5.24).

A partir destes pontos pode-se perceber que o perspectivismo de Nietzsche implica uma complexa pressuposição de posicionamentos e movimentos de aproximação e distanciamento com respeito a tendências científicas e filosóficas de seu tempo. Sua consideração da posição idealista ante o conhecimento baseado na relação sujeito-objeto, considerada como uma "falsificação da realidade" [Fälschung des Thatbestandes], decorrente de hábitos gramaticais [grammatischen Gewohnheiten] e conviç̧ões religiosas, refletem para ele o antigo atomismo e a ideia de força ou de algo que age sobre outras coisas. A negação de toda forma de estabilidade identitária é aspecto nuclear deste movimento, que resulta na pretensão de positivamente pensar sem um "algo" [es], sem uma substância (JGB/BM 17, KSA 5.32). Como tentamos mostrar, há nos escritos de Nietzsche inúmeros aspectos que possibilitam defender esta interpretação. Ele parece ver nas ciências naturais de seu tempo, e decisivamente em Boscovich, a desvinculação das especulações de pressupostos de demonstrabilidade totalmente vinculados à lógica causal da experiência sensível (Nachlass/FP, 26 [412], verão-outono de 1884, KSA 11.261), mas que segundo Nietzsche necessitam ser

61 Pois "a vontade de potência interpreta" (Nachlass/FP 2 [148], KSA 12.139).

Cad. Nietzsche, Guarulhos/Porto Seguro, v.39, n.1, p. 54-92, janeiro/abril, 2018. 
Barros, R. A. P.

adequadas ao pressuposto do aspecto moral de toda perspectividade, como forma preventiva ante a sedução moral da "verdade" e da posse definitiva de conhecimento. Disso prescinde sua filosofia, que de forma muito mais pertinente não deve ser entendida como dogma (Nachlass/FP 26 [432], KSA 11.266), mas antes como "provisória pesquisa regulativa" [vorläufige regulative Forschung], que possibilita associá-la a uma interpretação não metafísica, dinâmica, falibilista e evolucionária da ciência. Neste sentido, a título de conclusão, retornamos à conhecida, mas significativa passagem do parágrafo 374 de A gaia ciência:

Mas eu acho que nós estamos hoje no mínimo longe da risível impolidez de decretar do nosso ponto de vista [Ecke], que apenas deste ponto de vista é permitido ter perspectivas. Muito mais do que isso, o mundo se nos tornou novamente "infinito", tanto quanto nós não possamos rejeitar que ele comporta em si infinitas interpretações. Novamente nos toca o grande estremecimento, mas quem desejaria de imediatamente divinizar à maneira antiga esta monstruosidade de mundo desconhecido? E doravante adorar o desconhecido como "o desconhecido"? Há! São tantas possibilidades não divinas de interpretação computadas neste desconhecido. Tanta diabrura, disparate, loucura da interpretação, da nossa própria e mesma, humana, demasiadamente humana, que nós conhecemos.... (FW/GC 374, KSA 3.626)

88 Cad. Nietzsche, Guarulhos/Porto Seguro, v.39, n.1, p. 54-92, janeiro/abril, 2018. 


\begin{abstract}
Although the few references to the term, Nietzsche's notion of perspectivism is an important assumption of his philosophical reflection. It is a notion, as it will be tried to demonstrate, significant for the understanding of many theoretical positions of the author concerning science and knowledge and decisively for the interpretation of both notions as interpretative perspectives The following argument aims to analyze the influences and assumptions of this notion, highlighting its Kantian (Neokantian), Schopenhaurian background, but also considering influences outside of philosophy, such as Ruggero Boscovich's theoretical physics, which plays a decisive role in the formulation of the notions of perspectivism and perspectivist interpretation in Nietzsche's philosophy.
\end{abstract}

Keywords: Conscience, Subject, Perspectivity, Interpretation.

\title{
Referências bibliográficas
}

ABEL, Günter. Die Aktualität der Wissenschaftsphilosophie Nietzsches. In: Helmut Heit; Günter Abel; Marco Brusotti (Org.) Nietzsches wissenschaftsphilosophie. Berlin\Boston: Walter de Gruyter. 481 - 530.

BARROS, Roberto. O desdobramento do princípio de imanência em Nietzsche e Schopenhauer. In: Ruy Carvalho; Gustavo Costa; Thiago Mota (Org.) Nietzsche - Schopenhauer: Metafísica e significação moral do mundo. Fortaleza: UECE, 2015. $61-86$.

BONSIEPEN, Wolfgang. Hegel und der Neukanianismus. In: Thomas Wyrwich (Org.) Hegel in der neueren Philosophie. Hamburg: Felix Meiner Verlag, 2011. $47-112$.

BORSCHE, Tilman. Wozu Wissenschaft? Überlegungen zu Frage der Rangordnung im Wissenschaftsdiskurs nach Nietzsche. In: Helmut Heit; Günter Abel; Marco Brusotti (Org.) Nietzsches wissenschaftsphilosophie. Berlin\Boston: Walter de Gruyter. $465-480$.

BRINKMANN, Klaus. Idealism Without Limits. Hegel and the Problem of Objectivity. Dorbrecht\Heildelberg\London\New York: Springer, 2011. 
Barros, R. A. P.

DELLINGER, Jakob. Relendo a perspectividade. Algumas notas sobre "O perspectivismo de Nietzsche”. São Paulo: Cadernos Nietzsche, 31, 2012. 127.

FREZZATTI, Wilson Antonio. Haeckel e Nietzsche: aspectos da crítica ao mecanicismo no século XIX. São Paulo: Scientia Studia, Vol I, No 4, 2003, 435-461.

GONÇALVES, Marcia, C. F. Schelling filósofo da natureza ou cientista da imanência? In: As filosofias de Schelling. Fernando Rey Puente e Leonardo Alves Vieira (Org). Belo Horizonte, Editora UFMG, 2005. 71 - 90.

HEGEL, G.W.F. Enciclopédia das Ciências Filosóficas em Compêndio (1830). Tradução: Paulo Meneses e José Nogueira Machado. São Paulo: Editora Loyola, 1995. Vol. I, II, III.

HEGEL, G.W.F. Fenomenologia do Espírito. Tradução: Paulo Meneses. Petrópolis: Editora Vozes, 2008.

HENRICH, Dieter. Between Kant and Hegel - Lectures on german Idealism. London: Harvard University press, 2003.

HOLZHEY, Helmut. Der Neukantismus in: Anton Hügli, Poul Lübcke (Org.), Philosophie in 20. Jahrhundert. Vol. 1. Hamburg: Rohwolt Tachenbuch Verlag, 2004. 19-44.

KANT, Immanuel. Kritik der reinen Vernunft. Frankfurt am Main: Surkamp, 1974.

KAULBACH, Friedrich. Philosophie des Perspektivismus. Tübingen: J.C.B. Mohr, 1990.

KOßLER, Mathias. Schopenhauer als Philosoph des Übergangs. In: Marta Kopij; Wojciech Kunicki (Org.) Nietzsche und Schopenhauer. Rezeptionenphänomene der Wendezeiten. Leipzig: Leipziger Universitätsverlag, 2006, 365 - 380.

LESNIEWSKA, Anna. Das Gewwissen der Philosophie. Schopenhauer und Nietzsche. In: Marta Kopij; Wojciech Kunicki (Org.) Nietzsche und Schopenhauer. Rezeptionenphänomene der Wendezeiten. Leipzig: Leipziger Universitätsverlag, 2006, $345-352$.

LOPES, Rogério. Filosofia e ciência: Nietzsche herdeiro do programa de Friedrich Albert Lange. In Miguel Angel de Barrenechea... [et al.]. Nietzsche e as ciências - Rio de Janeiro: 7 Letras, 2011. 13 - 29.

$90 \mid$ Cad. Nietzsche, Guarulhos/Porto Seguro, v.39, n.1, p. 54-92, janeiro/abril, 2018. 
MARQUES, António. A filosofia perspectivista de Nietzsche. São Paulo: Discurso Editorial:Ijuí: Editora Ijuí, 2003.

MAYERHOFER, Herta e VANECEK, Erich. Friedrich Albert Lange als Psychologe und Philosoph. Frankfuurt am Main: Peter Lang GmbH, 2007.

NASSER, Eduardo. Nietzsche e a ontologia do vir a ser. São Paulo: Loyola, 2015.

NIETZSCHE, Friedrich Wilhelm. Sämtliche Werke. Kritische Studienausgabe (KSA). Ed. G. Colli e M. Montinari. Munchen, de Gruyter/DTV, 1980.

OMNÈS, Roland. A filosofia da ciência contemporânea. São Paulo: Editora UNIFESP, 1994.

PEARSON, Keith Ansell. Boscovich's Influence on Nietzsche. Nietzsche Studien 20. Berlin - New York: Walter de Gruyter 2001. 5-33.

REDDING, Paul. Continental idealism. Leibniz to Nietzsche. London\New York: Routledge, 2009.

SCHNÄDELBACH, Herbert. Philosophie in Germany 1831 - 1833. Cambridge: Cambridge University Press, 1984.

SCHOPENHAUER, Arthur. Die Welt als Wille und Vorstellung. Zürich: Haffmans Verlag, 1999.

SEDGWICK, Sally. Idealism from Kant to Hegel. In: Sedgwick (Org.) The reception of Kans't critical Phylosophie by Fichte, Schelling and Hegel. Cambridge: Cambridge University Press, 2000, 1-18.

STACK, George J. Lange and Nietzsche. Berlin - New York: Walter de Gruyter, 1983.

STEGMAIER, Werner. „Wissenschaft“ als Vorurteil. Kontestuelle Interpretation des Aphorismus Nr. 373 der Fröhlichen Wissenschaft. In: Helmut Heit; Günter Abel; Marco Brusotti (Org.) Nietzsches wissenschaftsphilosophie. Berlin\ Boston: Walter de Gruyter. 25 - 37.

STONE, Alison. Philosophy of Nature in Michael Baur (Org.) Hegel Keycocepts. London\New York: Routledge, 2014. 91-102.

WHITLOCK, Greg. Roger Boscovich, Benedict Spinoza and Friedrich Nietzsche: The untold Story. Berlin - New York: Walter de Gruyter. Nietzsche Studien 25, 1996. 200-219. 
Barros, R. A. P.

WHITLOCK, Greg. Investigation in Time Atomism and eternal recurrence. Pennylvania: Journal of Nietzsche Studies. 20, 2000. $34-57$.

WUKETHTITS, Franz M. Evolutionsmodelle unser Denkenstrukturen bis zum 20. Jahrhundert. In: Rupert Riedl e Elfriede Maria Bonet (Org), Entwicklung der evolutionären Erkenntnistheorie. Wien: Verlag des Österreichen Stadts, 1987. 11-19.

Artigo recebido para publicação em 20/04/2017 Artigo aceito para publicação em 08/06/2017

92 | Cad. Nietzsche, Guarulhos/Porto Seguro, v.39, n.1, p. 54-92, janeiro/abril, 2018. 